\title{
Silent meningioma leading to death
}

\author{
Bhattacharya $\mathbf{P},{ }^{1}$ Chattopadhyay $\mathrm{S}^{2 *}$
}

${ }^{1}$ Department of Forensic Medicine, R. G Kar Medical College, Kolkata, India.

${ }^{2}$ Department of Forensic Medicine, Murshidabad Medical College, West Bengal, India

\section{*Corresponding Author: \\ Dr. Saurabh Chattopadhyay \\ 23/12 Gariahat Road, 1st Floor, \\ Ballygunge, Kolkata, India. \\ Pin - 700029 \\ Email: chattopadhyaydrs@rediffmail.com}

\section{Citation}

Bhattacharya $P$, Chattopadhyay S. Silent meningioma leading to death. Nepal Journal of Medical Sciences 2014;3(1):72-3.

\begin{abstract}
Benign intracranial meningiomas are seldom the cause of death in elderly. It may be the triggering factor for a sequence of events which may ultimately lead to death. The silent nature of such tumors leads to delay in diagnosis and thus proper management. Findings at autopsy may confirm the diagnosis and cause of death in such cases.
\end{abstract}

Keywords: Asymptomatic; autopsy; intracranial tumors; meningioma

\section{Introduction:}

Intracranial tumors are a known cause of morbidity and mortality among the elderly. Amongst the different types of benign brain tumors meningiomas are the most common. They are the most frequently reported primary intracranial neoplasm in the United States ${ }^{1}$ and in India it accounts for $9-15 \%$ of all intracranial neoplasm. ${ }^{2}$ The incidence is higher in Africa 24-38\% . ${ }^{2}$ Undiagnosed intracranial space occupying lesions incidentally found during CT scan in old age or at autopsy have been reported. ${ }^{3}$ However deaths due to such undiagnosed meningiomas are rare. Most of the meningiomas are slow growing tumors and classically present with headache, seizures, neurodeficits, hemi paresis etc. Contrary to the common presentation a large number of such tumors are asymptomatic. Kuratsu et.al. ${ }^{4}$ in his study found $38.9 \%$ of the meningiomas to be asymptomatic.

\section{Case report:}

An 85 years old female presented to the emergency with a history of blackout and fall at her residence. On admission she was unconscious and a CT scan of the brain revealed subarachnoid hemorrhage over the right parietal and occipital lobe. A diagnosis of subdural hemorrhage on the left side temporal lobe and left cerebellar region was also made by the attending physician. No other significant findings on examination or past history could be elicited. She expired about 6 hours after admission.
Autopsy confirmed the presence of the subarachnoid hemorrhage as detected on CT scan. However no evidence of subdural hemorrhage was detected, whereas a tumor mass measuring $4.2 \mathrm{~cm} \times 3.5 \mathrm{~cm}$ X $1.5 \mathrm{~cm}$ was detected at the skull base with its root at the junction of the middle and posterior cranial fossa on the left side. (Figure 1). The left cerebellar lobe was compressed. On macroscopic examination it was encapsulated and showed multicystic and hemorrhagic areas. Histological examination proved it to be a fibroblastic meningioma with extensive areas of hemorrhage, congestion and necrosis.

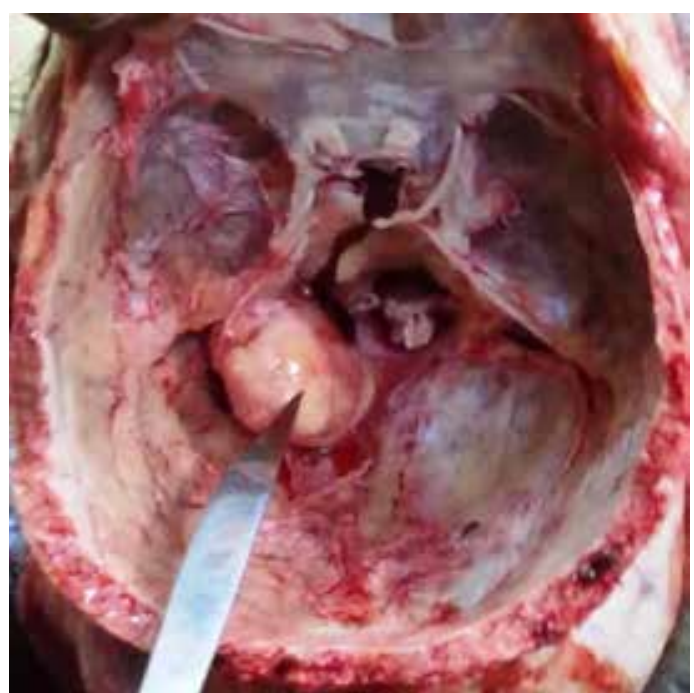

Figure 1: Tumor mass in situ 


\section{Discussion:}

The incidence of asymptomatic meningiomas is higher in individuals above the age of 70 years and more so among females $^{4}$ Nakasu et al. ${ }^{5}$ in their study found that in $2.3 \%$ of all autopsies, meningiomas are detected incidentally. In our case also the meningioma was asymptomatic and detected incidentally on autopsy. However it was the precipitating factor for the blackout and fall which resulted from the mass effect and compression over the cerebellum. The subarachnoid hemorrhage was the result of the fall and vessel rupture. The subdural hemorrhage in the left temporal and cerebellar region as noted on CT scan was actually the misinterpretation of the meningioma located at the skull base. Pruna et al. ${ }^{6}$ have reported that calcified chronic subdural hematoma may sometimes be confused as calcified meningiomas. Thus the reverse may also be held true as in the present case. In most of the cases reported meningiomas are benign tumors and rarely cause death. In the present case though the tumor was not the immediate cause, however it was the antecedent cause of death. As these are silent tumors their presentations are also varied. Fraser $^{7}$ has reported a case where delayed recovery from general anesthesia led to a diagnosis of meningioma. Adhiyaman $^{8}$ reports that meningiomas may also present with Parkinsonism. It is quite un usual for a tumor mass of $4.2 \mathrm{~cm} X 3.5 \mathrm{~cm} X 1.5 \mathrm{~cm}$ size to be asymptomatic. In our case the first symptom of presentation was the black out and fall resulting in subarachnoid hemorrhage terminating in death. Conclusion: The silent nature of the slow growing tumors may delay the diagnosis. Moreover misinterpretation of CT scan findings may also alter the management in such a case. High index of suspicion may be helpful in early diagnosis and proper management of such cases.

\author{
Conflict of interest: None \\ Funding: None
}

\section{References:}

[1]. Claus EB, Bondy ML, Schildkraut JM, et al. Epidemiology of Intracranial Meningioma. Neurosurgery. 2005;57:1088-95. http://dx.doi. org/10.1227/01.NEU.0000188281.91351.B9

[2]. Thamburaj AV. Inrtacranial meningiomas. Available at; www.thamburaj.com Accessed on 30 Oct 2011.

[3]. Niiro M, Yatsushiro K, Nakamura K, et Al. J Neurol Neurosurg Psychiatry 2000;68:25-

8. http://dx.doi.org/10.1136/jnnp.68.1.25

[4]. Kuratsu J, Kochi M, Ushio Y. Incidence and clinical features of symptomatic meningiomas. J Neurosurg 2000;92:766-70. http://dx.doi.org/10.3171/jns.2000.92.5.0766 [5]. Nakasu S, Hirano A, Shimura T, et al. Incidental meningiomas in autopsy. Surg Neurol. 1987;27:31922.http://dx.doi.org/10.1016/0090-3019(87)90005-X [6]. Pruna V, Bucur N, Neacsu A, et al. Calcified chronic subdural hematoma $-\mathrm{A}$ case report. Romanian Neurosurgery 15:22-5. [7]. Fraser AC, Goat VA. Unrecognised presentation of a meningioma. Delayed recovery after general anesthesia presenting as a sign of intracranial pathology. Anasthesia 1983;38:128. http:// dx.doi.org/10.1111/j.1365-2044.1983.tb13930.x [8]. Adhiyaman V, Meara J. Meningioma presenting as bilateral Parkinsonism. Age and Ageing 2003;32:456-8. http://dx.doi.org/10.1093/ageing/32.4.456 